\title{
La red de garantía de ingresos en España en tiempos de crisis. Las rentas mínimas de inserción frente a la alternativa de la renta básica
}

\author{
Borja Barragué Calvo \\ Investigador del Departamento de Derecho Público y Filosofía Jurídica \\ Universidad Autónoma de Madrid
}

Recibido: 23.11 .09

Aceptado: 15.12.09

Resumen: El impacto de la crisis sobre el empleo ha puesto de manifiesto una de las principales carencias de la política social en España: la ausencia de una última red de garantía de ingresos que ofrezca una mínima seguridad económica a la población. Si bien en los últimos diez años España ha experimentado fases de crecimiento económico importante, la proporción de personas bajo el umbral del $60 \%$ de la renta media, casi un quinto exacto del total de la población, se ha mantenido constante. Es probable por tanto que, habiendo fracasado en el objetivo de reducir la proporción de pobres con tasas de crecimiento económico sustanciales, unas tasas negativas o muy escasamente positivas comporten un crecimiento significativo de la pobreza. El trabajo lleva a cabo un análisis de los programas de rentas mínimas en la Europa meridional, donde el haber quedado al margen de las políticas fiscales keynesianas durante la era fordista ha supuesto un significativo subdesarrollo social. A la luz de estas experiencias, el artículo sostiene que la incidencia de estos programas en la erradicación de la pobreza extrema ha sido escasa y su capacidad de respuesta ante la crisis prácticamente nula, por lo que concluye con la propuesta de un programa de renta básica.

Palabras clave: Crisis, pobreza, justicia social, rentas mínimas, renta básica.

Abstract: The impact of the economic crisis on employment has revealed one of the main lacks of the social policy in Spain: the absence of an ultimate safety net which offers a minimum economic security to the population. Poverty levels in Spain have remained very similar during the last decades. However, the economic crisis is raising the percentage of people under the poverty line fast. During the past ten years, we have needed substantial rates of economic growth to maintain the proportion of poor people close to 20\%; it is highly probable that the current situation significantly increases that proportion. The paper aims to contribute to the analysis of the minimum wages programs in southern Europe, by critically analyzing the impact of not having participated in the Keynesian fiscal policy during the fordist era on their present social underdevelopment. In view of this, the article holds that the actual incidence of the minimum wages in eradicating extreme poverty has been low and that their responsiveness to economic crisis almost null, so concludes presenting the Basic Income proposal.

Key words: Crisis, poverty, social justice, minimum wages, basic income. 
Sumario: Un contexto de crisis económica.-1. La situación social en el mundo. 1.1. Cambios en el nivel macroeconómico y pobreza. 1.2. Algunos datos. 1.3. Las dimensiones de la globalización. 1.4. Las desigualdades sociales en el contexto de la globalización. 1.5. Las causas de la situación social en el ámbito internacional: la concepción de la igualdad del liberalismo económico.-2. La situación social en Europa. 2.1. Cambios en el marco de la producción y del trabajo. 2.1. La situación social en la Europa del Sur. 2.2. Los sistemas de garantía de ingresos en la Europa del Sur: algunos datos. 2.3. Los agujeros de las mallas de seguridad en España. 2.4. Causas de la escasa protección de las rentas mínimas. 2.4.1. Causas de naturaleza práctica. 2.4.2. Causas de carácter ideológico.-3. La propuesta de la Renta Básica.

\section{Un contexto de crisis económica}

Han transcurrido ya más de sesenta años desde que el 10 de diciembre de 1948 la Asamblea General de las Naciones Unidas proclamó la Declaración Universal de Derechos Humanos y, desde entonces, los cambios políticos, sociales, económicos, tecnológicos y científicos que han ido transformando las sociedades -tanto las nacionales como la internacional- han provocado que ni sus valores, ni sus instituciones, ni sus necesidades en materia de derechos humanos sean las mismas. En efecto, los últimos años han venido marcados por la discusión en torno al nuevo contexto en el que nos movemos. Un contexto que se ha dado en llamar globalización y que ahora ha de dar cuenta también de la situación de crisis económica actual y del impacto que esta va a tener sobre el empleo.

Al hilo de estas consideraciones, importa señalar que a pesar de que se trata de una crisis financiera cuyo origen parece hallarse en los Estados Unidos, la intensa internacionalización de la actividad económica mundial ha provocado que sus efectos se estén sintiendo en todo el mundo. Esta es, tal vez, una de las diferencias más notables respecto de la crisis de 1929: su mayor impacto sobre el comercio y las finanzas de la economía global.

Para el caso de España, algunas cifras ilustran la magnitud del problema. Ninguna previsión alertó de que la tasa de desempleo en España llegaría a situarse en el 18,9\% en el segundo semestre, con lo que se empeoraba así en 7,1 puntos el dato respecto a hace un año y superando en más de 10 puntos la media de los Estados de la $\operatorname{OCDE}(8,6 \%)^{1}$.

El impacto de la crisis sobre el empleo ha puesto de manifiesto una de las principales carencias de la política social en España: a saber, la ausencia de una última red de garantía de ingresos que ofrezca una mínima seguridad económica a la población. Salvo excepciones, los programas autonómicos introduci-

${ }^{1}$ El País, 13 de octubre de 2009. 
dos a lo largo de los años ochenta y noventa no ofrecen a las personas en riesgo recursos suficientes para cubrir sus necesidades básicas. Incluso en sus formas más extremas, la pobreza sigue constituyendo un serio problema.

El porcentaje de pobres en España no ha variado significativamente en los últimos 30 años anteriores a la crisis, y se han situado siempre en torno al 20\%. Cuando el crecimiento económico ha sido importante, y en ocasiones incluso muy notable, la proporción de personas bajo el umbral del $60 \%$ de la renta media, casi un quinto exacto del total de la población, se ha mantenido constante a lo largo de las últimas décadas. Es probable, por tanto, que habiendo fracasado en el objetivo de reducir la proporción de pobres con tasas de crecimiento económico substanciales, unas tasas negativas o muy escasamente positivas comporten un crecimiento significativo de la pobreza. La oportunidad de reabrir el debate sobre la modificación de algunos de los elementos de las «mallas de seguridad» en España parece ineludible.

\section{La situación social en el mundo}

Hoy por hoy la pertinencia de propuestas de reforma social viene dada fundamentalmente por dos circunstancias que se encuentran presentes en la mayoría de las sociedades modernas: el paro y la pobreza. Ocurre, además, que ambos hechos están íntimamente relacionados, de modo que, al menos en las sociedades desarrolladas, la pobreza está principalmente causada por el desempleo de larga duración. Por ello parece recomendable repasar, siquiera brevemente, los antecedentes inmediatos que han contribuido a dar forma al actual mercado de trabajo. Para ello nos detendremos en primer lugar en el período comprendido entre el final de la II Guerra Mundial en 1945 y la crisis del petróleo de 1973.

Tras el final de la II Guerra, los Estados asumen la reconstrucción de las instituciones políticas, seriamente dañadas a consecuencia de la guerra. Esta fuerte intervención, propia de la visión keynesiana y aplicada en el modelo socioproductivo fordista, se instrumentaba a través de un modelo económico conocido como «círculo virtuoso del fordismo». Su funcionamiento se basaba en la alta productividad del sistema (resultado del desarrollo y profundización del principio mecánico aplicado a los procesos de trabajo) y la elevada necesidad de mano de obra, que deriva necesariamente en una situación de pleno empleo estable y una casi marginal tasa de paro friccional. Esta secuencia, aparentemente sin fisuras y que da como resultado sociedades bien integradas, basadas en el pleno empleo y con una redistribución de la riqueza satisfactoria para la mayoría, entra empero en crisis a comienzos de los setenta ${ }^{2}$.

\footnotetext{
${ }^{2}$ En realidad, esta sociedad del pleno empleo «sin fisuras» es bastante limitada tanto históricamente, como en términos geográficos y de género. Tal y como señala F. Miguélez en «¿Por qué empeora el empleo?», Sistema, núms. 168-169, la situación del pleno empleo
} 
Esta segunda fase tiene su inicio en la crisis de 1973, cuyo detonante fue el alza de los precios del petróleo decretada por los países exportadores. Esta nueva etapa económica va a conocer tanto grandes transformaciones en el marco general de la economía, como cambios más encuadrados en el ámbito de la organización de la producción y del trabajo.

\subsection{Cambios en el nivel macroeconómico y pobreza}

En lo atinente al primer grupo de cambios (cambios en el nivel macroeconómico), desde los inicios de los ochenta son ya observables los procesos de globalización. La noción más extendida del término globalización denota una situación en la que tanto el mercado como las empresas que operan en él han pasado a ser transnacionales, y han eludido las regulaciones de los Estados nacionales en sus actividades. Desde esta perspectiva económica, la globalización implica, por tanto, un nuevo contexto muy diferente al surgido tras el final de la II Guerra Mundial, cuando los Estados sociales se extendieron en Occidente como la forma generalmente aceptada de organización político-social. Dado que la globalización ha adquirido su mayor protagonismo en estos últimos 25 años, es lógico que nos preguntemos si tal fenómeno ha tenido impacto o no en la pobreza mundial.

\subsection{Algunos datos}

De la mano de la globalización, desde 1950 el Producto Mundial Bruto -suma del Producto Nacional Bruto de todos los países- se ha multiplicado por siete y la renta per cápita por tres. En la línea apuntada por estos datos, en mayo de 2001 el Banco Mundial publicó su informe Globalization, Growth and Poverty: Building an Inclusive World Economy, en el que se destaca la siguiente conclusión: como resultado del proceso de globalización, la pobreza había descendido 200 millones en el periodo comprendido entre 1980 y 1998, y definen la pobreza como el consumo menor o igual a un dólar estadounidense. Ahora bien, tal definición presenta problemas. A las personas se les pregunta qué han comprado, pero no si tienen o no acceso a servicios públicos como sanidad o educación, y se les interroga acerca del volumen total de lo adquirido durante un mes, con lo que las respuestas son más imprecisas que cuando se les pregunta por lo consumido la semana anterior. Es más, como consecuencia de que la gran mayoría de personas que viven en países pobres son pobres, cuando se han realizado encuestas sobre el alimento ingerido según las necesidades definidas científicamente, los niveles

estable es un fenómeno de los países ricos o centrales, que en algunos casos se prolongó durante 40 años, pero en otros no más de $20 \mathrm{y}$, sobre todo, aplicable exclusivamente al empleo masculino, en particular al del «cabeza de familia». 
de pobreza hallados duplican prácticamente los de los estimados según el criterio del consumo igual o menor a un dólar por día ${ }^{3}$. Pero si ampliamos nuestro enfoque para incluir en él datos procedentes no solo del Banco Mundial, nos encontramos con que la economía global se ha gestionado de tal modo, que casi la mitad de la población mundial vive en la pobreza ${ }^{4}$, el mismo porcentaje aproximadamente vive en países con una desigualdad creciente ${ }^{5}$ y el número total de desempleados es de 190 millones de personas ${ }^{6}$.

\subsection{Las dimensiones de la globalización}

Pero las cosas no son tan sencillas. Ulrich Beck, por ejemplo, distingue entre globalismo, globalidad y globalización. El primero hace referencia a la ideología que sustenta el capitalismo global ensalzando el mercado y rechazando cualquier actividad social del Estado; según esta ideología la economía es la única variable a tener en cuenta. Por globalidad entiende la constitución de una sociedad mundial, en que los espacios aislados e impermeables no son posibles ya que ningún país ni grupo social dentro de estos es capaz ya de vivir al margen de los demás. Por último, la globalización comprende aquellos procesos a cuyo través los Estados nacionales se imbrican mediante la actuación de agentes transnacionales. Desde esta triple óptica, que las relaciones económicas internacionales han existido siempre es una evidencia. Ya los fenicios navegaban el mar Mediterráneo con el propósito de comerciar con otros pueblos. La novedad de lo que se ha dado en llamar globalización no puede radicar, por consiguiente, en las relaciones comerciales que se establecen entre empresas o particulares de diversas nacionalidades, sino en la ideología que acompaña a una internacionalización del comercio y de la producción alrededor de las economías. En efecto, es una falacia presentar el debate en términos de una confrontación entre quienes apoyan y promueven la globalización de la actividad económica y quienes se oponen a ella. Tal discusión es una falsedad; el punto que habría que debatir no es si se quiere o no una internacionalización del comercio, sino el establecimiento de los criterios que deben regirla: es decir, si esta debe realizarse mediante la desregulación de los mercados laborales y financieros, por cuanto los principales problemas económicos y sociales de nuestro tiempo provienen de la excesiva intervención del Estado y de la insuficiente libertad que tiene la iniciativa privada, o si por el contrario conviene que el Estado

${ }^{3}$ Vicenç Navarro: El subdesarrollo social de España. Causas y consecuencias, Ed. Anagrama, Barcelona, 2006, p. 229.

${ }^{4}$ Prog. Naciones Unidas para el Desarrollo, Informe sobre desarrollo humano 2007/2008.

${ }^{5}$ Comisión Mundial sobre las Dimensiones Sociales de la Globalización, Por una globalización justa: crear oportunidades para todos, Organización Internacional del Trabajo, 2004. Documento disponible en <http://www.ilo.org/>.

${ }^{6}$ Organización Internacional del Trabajo, Tendencias Mundiales del Empleo 2008. 
intervenga en la actividad económica ya que no siempre la libertad conduce a la felicidad de la sociedad. Una cuestión que hasta el momento permanece relativamente indiscutida es la enorme influencia que desde los inicios de los ochenta ejerció el pensamiento de autores como Friedrich Von Hayek y Milton Friedman, no solo en los Gobiernos de Margaret Thatcher en el Reino Unido y de Ronald Reagan en Estados Unidos, sino también en la doctrina de las grandes organizaciones internacionales como el FMI y el BM.

\subsection{Las desigualdades sociales en el contexto de la globalización}

$\mathrm{Al}$ igual que ocurría con la pobreza, las desigualdades sociales también varían en función de que se midan por el índice Gini o bien por otros métodos, de forma que las respuestas a la pregunta de si la eliminación de barreras y aranceles en el comercio internacional ha reducido o no las desigualdades varían. Y aún más cuando se introduce la consideración de si hemos de atender solamente a las desigualdades entre países o si hemos de incluir asimismo las existentes dentro de cada país. Ahora bien, dentro de esa variabilidad hay ciertas pautas que merecen ser señaladas.

Desde que en 1947 se realizaron los primeros estudios, en EE. UU. el coeficiente de Gini no había alcanzado nunca antes de 1990 el 0,40, y a partir de entonces se viene situando siempre por encima de esa cifra. En este sentido, Gar Alperovitz sostiene que, a pesar de que al hablar de las desigualdades sociales en EE. UU. existe cierta tendencia a hacerlo de forma poco rigurosa y en trazo demasiado grueso, la realidad de los datos es mucho más dramática de lo que la gente está dispuesta a aceptar. El 1\% de la población (más rica) obtiene cada año ingresos superiores a los de los 100 millones de americanos más pobres conjuntamente. El 1\% de la población más rica posee casi el $50 \%$ de todo el capital de inversión. Otra elite social, el 5\% más rico, posee casi el $70 \%$ de toda la riqueza financiera del país. Y esto si ceñimos nuestro análisis a los EE. UU., porque al ampliar el objeto de estudio a la escena internacional los datos son aún más alarmantes. Aquí el 1\% de la población mundial más rica obtiene cada año ingresos equivalentes a los del $57 \%$ más pobre tomados conjuntamente. Y el $5 \%$ de la población más rica tiene ingresos 114 veces superiores a los del 5\% más pobre ${ }^{7}$. En comparación con EE. UU., Europa presenta sistemáticamente cifras propias de sociedades más cohesionadas, con índices de Gini más bajos y tasas menores de pobreza. El problema de los países europeos se encuentra, como se discutirá más abajo (2.1), en sus elevadas tasas de paro.

\footnotetext{
${ }^{7}$ G. Alperovitz: «Time to Get Serious about Inequality and Sustainability», Synthesis/ Regeneration 38, 2005, pp. 1-2.
} 


\subsection{Las causas de la situación social en el ámbito internacional: la concep- ción de la igualdad del liberalismo económico}

Es ya habitual escuchar que los científicos que trabajan en cuestiones relacionadas con el bienestar social son aquellos que sostienen concepciones de la justicia social igualitarias. Pero así formulada esta afirmación es muy poco informativa, pues un problema preliminar relacionado con la idea de justicia es que, como señalara Bertrand Russell, apenas disponemos de un concepto preciso que haya obtenido general aceptación ${ }^{8}$.

Respecto a la diversidad de sentidos del concepto de justicia, ya Aristóteles dejó establecido que «lo justo es lo legal y lo equitativo» ${ }^{9}$. En el primer sentido, la justicia es el cumplimiento de la ley, «porque la ley manda vivir de acuerdo con todas las virtudes y prohíbe que se viva en conformidad con todos los vicios» ${ }^{10}$. En el segundo, la justicia es lo equitativo y comprende dos especies: «una especie es la que se practica en las distribuciones de honores, o dinero o cualquier otra cosa que se reparta entre los que tienen parte en el régimen [...] y otra especie es la que regula o corrige los modos de trato» ${ }^{11}$. Aristóteles denomina justicia distributiva a la referida al reparto -según los méritos de cada cual- entre los que tienen parte y justicia correctiva a la que regula los intercambios de bienes y las sanciones penales.

Siguiendo al estagirita, «parece que la justicia consiste en igualdad, y así es, pero no para todos, sino para los iguales; y la desigualdad parece ser justa, y lo es en efecto, pero no para todos, sino para los desiguales» ${ }^{12}$. De esta definición de la justicia como igualdad podemos extraer dos criterios de justicia; uno de igualdad estricta o aritmética, según el cual los casos iguales han de tratarse de la misma manera y aplicable a la esfera de la justicia correctiva, y otro de igualdad proporcional o geométrica, de acuerdo con el cual los casos desiguales han de tratarse de forma desigual, aplicable al ámbito de la justicia distributiva.

Así delimitados los diversos conceptos -como legalidad o como equidad- y ámbitos -según la apliquemos a las distribuciones o a los intercambios- de la justicia, aquí nos centraremos en el ámbito de la justicia distributiva, por cuanto las diversas concepciones de la justicia social se ocupan del modo como se distribuyen los bienes económicos y las oportunidades. Son

\footnotetext{
${ }^{8}$ Para B. Russell «la palabra justo es muy ambigua, y no resulta nada fácil discernir los diversos significados que tiene en el lenguaje común», Ensayos Filosóficos, Alianza Editorial, Madrid, 1969, p. 29.

${ }^{9}$ Aristóteles: Ética a Nicómaco, V, 1129 ab, edición de M. Araujo y J. Marías, Centro de Estudios Constitucionales, Madrid, 1989.

${ }^{10}$ Ibídem, V, 2, 1130 b, 24-25.

${ }^{11}$ Ibíd., V, 2, 1130 b, 30-33; 1131 a, 3.

${ }^{12}$ Política, III, 9, 1280 a, 11-14, edición de M. Araujo y J. Marías, Centro de Estudios Constitucionales, Madrid, 1989.
} 
tres las concepciones de la justicia distributiva más influyentes en la filosofía política moderna: la concepción liberal igualitaria, la marxista y la liberal clásica. Estos tres enfoques de la justicia distributiva se corresponden a su vez con tres formas de entender la igualdad: la igualdad de oportunidades, la igualdad de resultados y la igualdad ante la ley. Puesto que los propios Hayek y Friedman afirman frecuentemente que no hacen sino reiterar el antiguo credo de los fundadores del liberalismo clásico, en especial el de Adam Smith, parecería entonces interesante estudiar, siquiera de forma sucinta, el concepto de igualdad de esta tradición de pensamiento que desde los inicios de los ochenta ha venido ejerciendo una influencia tan determinante en las políticas de los Gobiernos occidentales más visibles y de organizaciones internacionales como el FMI y el BM.

Más allá de las figuras de F. Hayek y M. Friedman, ocupados fundamentalmente en asuntos de naturaleza económica, la filosofía política neoliberal tiene en Robert Nozick una de sus figuras centrales. De acuerdo con este filósofo, una persona puede adquirir «un derecho de propiedad permanente y transferible por herencia sobre una cosa que antes no era de nadie» siempre que «[no] empeore por eso la posición de otras que ya no tienen libertad para utilizarla ${ }^{13}$. Puesto que la apropiación inicial lleva aparejado el derecho de transferencia, una vez que las personas adquieren propiedades se hace necesario un mercado libre para los recursos productivos.

En el escenario de este mercado libre, la principal razón que el liberalismo económico esgrime en contra de la rectificación de las desigualdades es la denominada objeción de la «pendiente resbaladiza». Según esta objeción, el intento de rectificación de algunas desigualdades injustas podría derivar, pues para algunos autores neoliberales como F. Hayek parece no haber término medio entre la libertad de mercado y la economía planificada, en un intervencionismo estatal abusivo e irrespetuoso con las libertades personales. Para este nuevo liberalismo ${ }^{14}$, la distribución de la riqueza es un caso de justicia procedimental pura donde basta con que el procedimiento se lleve a cabo correcta y limpiamente para que el resultado sea justo. Y es que la neutralidad del Estado o, por decirlo parafraseando a Rawls, la elaboración de una teoría de la justicia donde la concepción pública de justicia sea política y no metafísica ${ }^{15}$, es una vieja aspiración del liberalismo. Importa señalar

${ }^{13}$ Robert Nozick: Anarchy, State, and Utopia, Basic Books, inc., Nueva York, 1974, p. 178.

${ }^{14}$ Francisco Vergara observa que «los estudiosos del pensamiento ultraliberal de los últimos años, especialmente el de Milton Friedman y Friedrich Hayek, han observado algunas diferencias entre estos pensadores y los liberales clásicos. Mientras que estos últimos, por ejemplo, apoyaban la educación pública, los ultraliberales rechazan la intervención del Estado en este ámbito»; Introducción a los fundamentos filosóficos del liberalismo, Alianza, Madrid, 1999, p. 11.

${ }^{15}$ John Rawls: «Justice as Fairness: Political not Metaphysical», Philosophy and Public Affairs, vol, 14, N. 3 (verano, 1985), pp. 223-251. 
que en sus versiones más refinadas esto no significa que toda ley o política se tengan que discutir de forma que se evite invocar cualquier concepción del bien, sino tan solo que las reglas de toma de decisiones no deben dar ninguna ventaja especial a determinadas concepciones del bien sobre las demás. Esta es una de las principales bases normativas sobre las que se asienta el liberalismo, cuyo proyecto pretende ser una respuesta a los problemas de decisión colectiva que surgen cuando gente con diferentes concepciones del bien se halla en busca de un conjunto de reglas básicas que ofrezca a cada persona la posibilidad de obrar mejor de lo que ninguna de ellas podría razonablemente esperar en el caso de que cada uno decidiera perseguir el bien egoístamente y sin restricciones. En efecto, es la tradición que arranca en Hobbes. Pero ¿en qué tipo de reglas estarían de acuerdo las partes preocupadas de promover sus intereses personales más eficazmente?

Es razonable suponer que las reglas pertenecerían a dos amplias clases: las legales y las morales ${ }^{16}$. Pero es dudoso que un sistema de reglas morales tenga alguna operatividad en una sociedad formada por gente egoísta. Más aún, resulta difícilmente inteligible cómo en una sociedad de personas egoístas puedan llegar a existir normas morales, pues al aceptar que la crítica de personas cuya autoridad reconocemos provoca sentimientos de culpa o remordimiento estamos también reconociendo la existencia de motivaciones que van más allá del mero egoísmo. Los pactos que se alcanzan a la luz de modelos de la justicia entendida como provecho mutuo no son sino acuerdos temporales cuya vigencia depende de que se mantenga el equilibrio de fuerzas entre las partes que hizo posible el consenso, por cuanto fracasa a la hora de proporcionar una base moral estable que sustente las reivindicaciones de los más desprovistos de poder en la negociación. Es decir, si la situación social mundial no ha mejorado desde que M. Thatcher en el Reino Unido y R. Reagan en EE. UU. llegaron al poder a pesar de que desde 1950 el Producto Mundial Bruto -suma del Producto Nacional Bruto de todos los países- se ha multiplicado por siete y la renta per cápita por tres, ello no es el efecto azaroso de un conjunto de decisiones políticas bienintencionadas pero fracasadas, sino la consecuencia de un enfoque de la justicia donde el resultado de las distribuciones castiga la posición del relativamente más débil mientras premia la del más poderoso.

\section{La situación social en Europa}

Decíamos más arriba que a partir de 1973 comienza una nueva etapa económica que va a conocer tanto grandes transformaciones en el marco general de la economía, en el nivel macroeconómico, como cambios más

${ }^{16}$ B. Barry: Justicia como imparcialidad, Paidós, Barcelona, 1997, pp. 59 y ss. 
encuadrados en el ámbito de la organización de la producción y del trabajo. El debilitamiento del Estado es una característica común a ambas dimensiones. En efecto, se adopta en este nuevo período económico la idea del «Estado mínimo», de acuerdo con la cual el Estado debe interferir lo mínimo en la regulación de la economía.

\subsection{Cambios en el marco de la producción y del trabajo}

El paso de la sociedad industrial a la postindustrial, tecnológica e informacional ha supuesto importantes cambios. Desde mediados de la década de los setenta, y de conformidad con un juicio casi unánimemente compartido por la doctrina, se observa un cambio de rumbo en el ordenamiento laboral de la mayoría de los países desarrollados. A resultas de la crisis económica habida en la primera mitad de esa década y del resurgimiento de las tesis liberales, podría decirse que en ese momento comienza a operarse una ruptura con lo que se conocía como la «sociedad del trabajo» o «sociedad salarial», de modo que si esta se caracterizaba por un creciente grado de homogeneidad laboral y por la participación creciente de los trabajadores en los beneficios del crecimiento, a partir de entonces comienza la lenta pero constante implantación de un nuevo paradigma organizativo conocido como estrategia de especialización flexible.

La noción más comúnmente aceptada de esta estrategia se refiere a ella como «forma de organizar el proceso de elaboración de bienes y de prestación de servicios mediante el recurso a la contratación de proveedores y suministradores externos para la ejecución de ciertas fases o actividades $»^{17}$. Estos cambios, que no se habrían traducido en un único tipo de organización empresarial, tienen sin embargo un elemento común a todos ellos: han dado como resultado la formación de la «empresa red», configurada como una empresa (matriz) que establece una red de contactos con empresas menores especializadas en una parte del ciclo productivo. Así, esta empresa madre se caracteriza por dos circunstancias: la fragmentación del ciclo de producción y su exteriorización.

De todos los efectos que se derivan de estas nuevas formas de organización de la empresa, el que aquí más nos interesa es el relacionado con la degradación de las condiciones del trabajo. En efecto, el masivo recurso de las empresas colaboradoras y auxiliares de la principal a las modalidades de contratación temporal y de trabajo a tiempo parcial ha desembocado en un peligroso proceso que Robert Castel ha denominado de invalidación social ${ }^{18}$, en

${ }^{17}$ Véase, por ejemplo, Fernando Valdés Dal-Ré: «Descentralización productiva y desorganización del Derecho del Trabajo», Revista de Ciencias Sociales, núm. 168-169, 2002, donde se aportan abundantes referencias bibliográficas en este mismo sentido.

${ }^{18}$ Cfr. Robert Castel: Les metamorphoses de la question sociale. Une chronique de salariat, París (Gallimard), 1999, pp. 28-29. 
clara referencia a la dualización del mercado de trabajo impulsada por la descentralización productiva ${ }^{19}$.

En 2004 el Fondo Monetario Internacional publicó un informe en el que se concluía que la causa de que el fortalecimiento de la recuperación económica estuviera encabezado por Estados Unidos se debía, entre otras, a que tiene un mercado laboral más desregulado (despedir a un trabajador, por ejemplo, resulta más barato) ${ }^{20}$ y una protección social más austera (no existe cobertura universal de los servicios sanitarios). De esta lectura del éxito de la economía estadounidense se desprenden las recomendaciones de los directores del Fondo Monetario Internacional para los países miembros de la Unión Europea: flexibilizar mediante su desregularización los mercados laborales y reducir el gasto público en las transferencias y servicios públicos de bienestar. El problema es que la situación social de los países que conforman la Unión Europea dista de ser homogénea.

\subsection{La situación social en la Europa del Sur}

En un trabajo ya clásico sobre la cuestión, Gosta Esping-Andersen distinguía tres modelos de Estado de bienestar atendiendo principalmente a seis criterios: $1^{\circ}$ ) las reglas de acceso que dan derecho a disfrutar de las instituciones de bienestar, distinguiendo básicamente entre dos modelos, el universalista y el selectivo; $2^{\circ} .^{\text {) }}$ las ayudas y subsidios en sí, estudiando tanto su cuantía como su volumen; $3 .^{\circ}$ ) las formas de financiación, analizando si las instituciones de bienestar se financian a través de impuestos o vía cotizaciones; $4 .^{\circ}$ ) el protagonismo que los sindicatos y las organizaciones de trabajadores poseen en la negociación colectiva; $5 .^{\circ}$ ) el papel que se deja al mercado; $6 .^{\circ}$ ) el papel que en la provisión de bienestar juegan las familias. EspingAndersen distinguía un modelo liberal que se identificaría con los países

${ }^{19}$ La flexibilidad en el empleo no es per se una característica que haya de perjudicar en todo caso a los trabajadores. De hecho, el contrato a tiempo parcial puede ser una fórmula válida para aquellos empleados que quieran compatibilizar su vida familiar y laboral. Ocurre, empero, que la degradación del empleo viene asociándose en la mayoría de los países desarrollados (y en España significadamente) con la flexibilidad, porque esta suele ser impuesta unilateralmente, y en condiciones frecuentemente abusivas, a la mayoría de los trabajadores.

${ }^{20} \mathrm{En}$ el informe se puede leer que mientras que «el fortalecimiento de la recuperación mundial estuvo encabezado por Estados Unidos y un grupo de economías asiáticas», en Europa «el prolongado período que se requiere para que se materialicen los aumentos de las tasas de participación laboral requerirán la adopción de medidas concertadas lo antes posible para frenar, si no revertir, la caída del crecimiento per cápita [...] En este contexto, los directores hicieron hincapié en la importancia de llevar a cabo la reforma del mercado de trabajo y de los sistemas de pensiones», pues «las rigideces en los mercados de trabajo [...] retrasaron los ajustes después del estallido de la burbuja y de los ajustes dentro de la zona [euro]», Fondo Monetario Internacional, Informe Anual 2004, esp. pp. 17-19. 
anglosajones, un modelo conservador presente sobre todo en la Europa continental y un modelo socialdemócrata, propio de los países escandinavos ${ }^{21}$. Junto a estos tres, hoy es habitual añadir un cuarto modelo formado por los países del Sur de Europa gobernados por dictaduras autoritarias de escasa sensibilidad social durante la etapa de mayor desarrollo de los Estados de bienestar (1945-1980) $)^{22}$.

La cuestión del fortalecimiento y la consolidación de las mallas de seguridad de protección social han tenido una particular repercusión en la Europa del Sur. Se puede decir en términos generales que en aquellos países donde la familia ha jugado un papel importante en el mantenimiento del bienestar, como ha sido el caso de los países del Sur de Europa, el papel de la asistencia social ha sido marginal y las estrategias de lucha contra la pobreza limitadas. Sin embargo, y a medida que la familia está siendo sometida a un mayor estrés, su capacidad para funcionar como proveedor complementario de bienestar y asistencia doméstica es cada vez más incierta. Y es que, en realidad, el «contrato sexual» se basa esencialmente en el trabajo no remunerado de las amas de casa, cuya disponibilidad para tales tareas disminuye a medida que aumenta su participación en el mercado laboral ${ }^{23}$.

\subsection{Los sistemas de garantía de ingresos en la Europa del Sur: algunos datos}

Según datos de 1996, las transferencias sociales (excluidas las pensiones) reducían de uno a tres puntos porcentuales los niveles de pobreza en Grecia e Italia, si bien importa observar que su eficacia era ciertamente superior -aunque por debajo del promedio en la UE- en España y Portugal ${ }^{24}$.

${ }^{21}$ G. Esping-Andersen: Los tres mundos del Estado del Bienestar, trad. B. Arregui Luco, Edicions Alfons el Magnànim-IVEI, Valencia, 1993.

${ }^{22}$ En este mismo sentido, V. Navarro, J. Schmitt y J. Astudillo consideran que «España, Portugal y Grecia tienen un Estado de bienestar con características propias y distintas del resto de los países de Europa», en «La importancia de la política en la supuesta globalización económica. La evolución de los Estados del bienestar en el capitalismo desarrollado durante la década de los años noventa», Sistema, núm. 171, 2002, p. 6.

${ }^{23}$ El trabajo, sin ulteriores precisiones, ha sido equiparado hasta los años sesenta con el trabajo asalariado o remunerado en el mercado. Pero el empleo hace referencia solamente a una de las varias formas de trabajo, concretamente la del asalariado. Aquí baste indicar que las otras dos formas de trabajo (no asalariado) más comunes serían el trabajo voluntario y el doméstico.

${ }^{24}$ Luis Moreno, Manos Matsaganis, Maurizio Ferrera y Luis Capucha: «¿Existe una "malla de seguridad" en la Europa del sur? La lucha contra la pobreza y la exclusión social en España, Grecia, Italia y Portugal», en Digital. CSIC, Unidad de Políticas Comparadas (CSIC), Documento de Trabajo 03-17, 2003, p. 3. Documento de acceso abierto disponible en <http://hdl.handle.net/10261/1579>. 
De acuerdo con lo sostenido por Luis Moreno y otros en un trabajo que se pregunta por la existencia o no de una malla de seguridad en Europa del Sur, la modestia de las actuaciones para combatir la pobreza deben ser atribuidas, al menos en parte, a la incapacidad de hacer llegar los recursos a los pobres. Particularmente en Grecia e Italia, donde el problema es más grave, solo una de cada tres personas en el quintil más bajo de renta perciben prestaciones sociales, excluidas las pensiones ${ }^{25}$.

Por otro lado, la afirmación de que la situación de los Estados miembros de la Unión Europea se encuentra lejos de ser homogénea se apoya en las siguientes consideraciones: 1) mientras que Noruega es el país con mayor Índice de Desarrollo Humano del mundo ${ }^{26}$, Islandia el tercero, Países Bajos el sexto y Suecia el séptimo, España ocupa el puesto 15, Italia el 18, Grecia el 25 y Portugal el 3427; 2) al comparar el Producto Interior Bruto per cápita de los países expresado en valores de poder de compra -lo que elimina las diferencias en los niveles de precios entre países permitiendo las comparaciones de sus PIB- en un índice cuyos datos fueron calculados en 2008 para la UE-27 (y donde a la media de los 27 países de la Unión se le asigna el valor 100), mientras que Noruega obtiene un valor de 190,2, Irlanda de 136,6, Países Bajos 135,0 y Suecia 121,5, España obtiene un 103,4, Italia un 100,5 , Grecia un 93,9 y Portugal un 75,$5 ; 3$ ) en cuanto a la productividad laboral como PIB per cápita expresado en valores de poder de compra y donde la media UE-27 es igual a 100, si por un lado Noruega obtiene un 157,5, Irlanda un 131,4, Países Bajos 115,5 y Suecia 111,6, por el otro Italia logra un 108,3, España un 104,5, Grecia un 101,9 y Portugal 70,8; 4) en lo atinente al porcentaje del Producto Interior Bruto destinado a gastos de investigación y desarrollo, Noruega destinó en 2007 (último dato disponible) un 1,64, Islandia un 2,9, Países Bajos 1,7 y Suecia 3,6, mientras que España gastó un 1,27 , Portugal un 1,18 , Italia un 1,13 (2006) y Grecia $0,57^{28}$.

${ }^{25}$ E. Marlier y M. Cohen-Solal: «Social benefits and their redistributive effect in the EU», Statistics in Focus (Theme 3 9/2000). Eurostat, Luxemburgo.

${ }^{26}$ El Índice de Desarrollo Humano comprende tres dimensiones esenciales: 1) la capacidad de gozar de una vida larga y saludable, medida a través de la esperanza de vida al nacer; 2) la capacidad de adquirir conocimientos, medida mediante una combinación del grado de alfabetización de las personas adultas y el nivel de asistencia escolar del conjunto de niños, adolescentes y jóvenes (de 6 a 24 años); 3) la capacidad de contar con el acceso a los recursos que permitan disfrutar de un nivel de vida digno, medido por el PIB per cápita ajustado al poder adquisitivo del dólar en los Estados Unidos en 2007.

${ }^{27}$ Programa de las Naciones Unidas para el Desarrollo, Informe sobre Desarrollo Humano 2009, pp. 181 y ss.

${ }^{28}$ Los datos relativos al Producto Interior Bruto per cápita de los países expresado en valores de poder de compra, la productividad laboral como PIB per cápita en expresado en valores de poder de compra y el porcentaje del Producto Interior Bruto destinado a gastos de investigación y desarrollo pueden consultarse en la página web de Eurostat: $<$ http://epags.eurostat.ec.europa.eu/portal/page/portal/eurostat/home/>; los referentes al 
De la presentación de esta serie de datos se pueden extraer legítimamente un par de conclusiones. La primera es que convendría que las principales organizaciones internacionales tuvieran presente la extraordinaria heterogeneidad de las situaciones sociales presentes en los países miembros de la UE a la hora de emitir juicios y aconsejar la adopción de políticas que se presentan como adecuadas para el conjunto de los Estados de la zona; efectivamente, a la luz de los anteriores indicadores parece imaginable que una determinada recomendación del FMI tenga bastante sentido para Noruega, alguno para Portugal y ninguno para Bulgaria, y viceversa. La segunda es que una rápida lectura de estos indicadores parece confirmar lo apuntado por autores como Adam Przeworski en cuanto a la existencia de una correlación entre las variables de régimen democrático y alto desarrollo humano. Aunque se trata de una cuestión que requiere de multitud de matices.

\subsection{Los agujeros de las mallas de seguridad en España}

Durante el franquismo los programas de asistencia social eran muy escasos. De acuerdo con un esquema de bienestar típicamente conservador, las instituciones sociales franquistas jugaban un papel subsidiario respecto de la familia y las instituciones caritativas privadas gestionadas fundamentalmente por la Iglesia. A lo largo de la mayor parte del franquismo -y de manera muy acentuada en su fase autárquica (1940-1959)- la obsesión del régimen por mantener el equilibrio presupuestario retardó los cambios de la Hacienda Pública. A pesar de que el déficit del Estado alcanzó cifras altas entre 1940 y 1946 por motivo de los pagos atrasados de la guerra, el Plan de Estabilización de 1959 acentuó el carácter restrictivo de la política fiscal, característico de la etapa autárquica. Las primeras medidas del Plan pasaron por un descenso en el gasto público y una tímida reforma fiscal. Ello permitió que la media anual del saldo del Presupuesto del Estado entre 1952 y 1965 fuese positiva, mediante el diseño de una política fiscal restrictiva para el conjunto del periodo ${ }^{29}$. Pero lo que a primera vista puede aparecer como la introducción de cierta «veta liberal» en la doctrina económica del franquismo, en realidad reflejaba el estricto control al que se sometía al gasto público. Contrariamente a lo que ocurría en Europa durante los años cincuenta y

PIB per cápita, aquí: <http://epags.eurostat.ec.europa.eu/tgm/table.do?tab=table\&init= $1 \&$ plugin=1\&language=en \&pcode=tsieb010>; los relativos a la productividad laboral, aquí: $<$ http://epags.eurostat.ec.europa.eu/tgm/table.do?tab=table\&init=1\&plugin=1\&language=e n\&pcode=tsieb030>; y por último los que hacen al porcentaje del PIB destinado a investigación y desarrollo, aquí: <http://epags.eurostat.ec.europa.eu/tgm/table.do?tab=table\& init $=1 \&$ plugin $=1 \&$ language $=$ en $\&$ pcode $=$ tsiir $020>$.

${ }^{29}$ Francisco Comín: «La Hacienda pública en el franquismo autárquico, 1940-1959», en Autarquía y mercado negro: el fracaso económico del primer franquismo, 1939-1959, Carlos F. Barciela, ed., Ed. Crítica, 2003, pp. 247-272. 
sesenta, en que se expandían los principios keynesianos de la política fiscal, al Estado franquista de posguerra no se le encomendaban las tareas que por entonces comenzaban a asumir los Estados de bienestar.

Con la democracia, la Constitución Española de 1978 (CE) inauguró un período en que «los poderes públicos mantendrán un régimen público de Seguridad Social para todos los ciudadanos, que garantice la asistencia y prestaciones sociales suficientes ante situaciones de necesidad, especialmente en caso de desempleo» (art. $41 \mathrm{CE}$ ). De acuerdo con lo establecido en los artículos 149 y $148 \mathrm{CE}$, la legislación básica y régimen económico de la Seguridad Social es competencia exclusiva del Estado, mientras que en materia de asistencia social las comunidades autónomas podrán asumir competencias.

Los dispositivos para combatir la pobreza en España han ido apareciendo en distintos momentos (1987, «Plan Concertado para el Desarrollo de Prestaciones Básicas de Servicios Sociales de las Corporaciones»; 1995, «Ponencia para el Análisis de los Problemas Estructurales del Sistema de la Seguridad Social y de las Principales Reformas que deberán acometerse»; 2001, «I Plan Nacional de Acción para la Inclusión Social del Reino de España de 2001-03», etc.) y con distintas lógicas para cada uno de los colectivos protegidos. Se ha operado a través de una doble distinción; por un lado, se han distinguido los colectivos aptos y los no aptos (personas ancianas y discapacitadas) para el mercado laboral; por otro lado, se ha organizado su protección o bien como una extensión de la seguridad social contributiva (pues pertenecían a su ámbito de protección) o bien al margen de esta ${ }^{30}$. Pero cuando se plantea el debate sobre la reducción de la pobreza la atención recae frecuentemente en las rentas mínimas, seguramente porque, si bien el panorama es mucho más amplio e incluye los complementos de mínimos de pensiones, las pensiones no contributivas y los subsidios asistenciales por desempleo, aquellas imponen toda clase de pruebas del estado de necesidad de sus potenciales beneficiarios, de forma que llegan a un porcentaje extraordinariamente bajo de quienes de hecho se encuentran en ese estado. De acuerdo con Laparra y Ayala, puede estimarse que las rentas mínimas llegan en España a 7 de cada mil hogares, y alcanzan a un total de 114.157 perceptores en total en 2008. Pero incluso este reducidísimo nivel de cobertura general capta sesgadamente la realidad, ya que uno de cada tres perceptores se encuentra en el País Vasco ${ }^{31}$. Las disfunciones asociadas a las rentas mínimas de las CC. AA. se explican por su insólita insistencia en adoptar como

${ }^{30}$ Ilustra muy bien esta doble distinción el Gráfico 3 sobre «Programas de garantía de mínimos en el sistema español de protección social» que elaboran Miguel Laparra y Luis Ayala en «El Sistema de Garantía de Ingresos Mínimos en España y la respuesta urgente que requiere la crisis social», Colecciones FOESSA, p. 20.

${ }^{31}$ Ibíd., p. 32. 
presupuesto operativo un modelo social ya extinguido: el modelo del varón sustentador o male breadwinner model.

\subsection{Causas de la escasa protección de las rentas mínimas}

Sostiene Jon Elster que «hay básicamente dos tipos de argumentos a favor de [una] reforma [social]. Unos son consecuencialistas: la reforma se desea porque se cree que tendrá consecuencias buenas o deseables. Otros son deontológicos: se considera que la reforma es intrínsecamente valiosa ${ }^{32}$. La inexistencia en España de una malla de seguridad como garantía última de unos ingresos mínimos atiende a dos razones de distinta naturaleza: una de tipo práctico y que se relaciona con el deficiente funcionamiento de los programas autonómicos de rentas mínimas; y otra de carácter ideológico y vinculada a la concepción de la igualdad como caridad.

\subsubsection{CAUSAS DE NATURALEZA PRÁCTICA}

A partir del acuerdo entre los Gobiernos central, autonómico y local posibilitado por el «Plan Concertado para el Desarrollo de Prestaciones Básicas de Servicios Sociales de las Corporaciones», todas las comunidades autónomas comenzaron a poner en marcha programas de rentas mínimas al amparo del artículo $149 \mathrm{CE}$. El primero se introdujo en Euskadi, mediante el Decreto 39/1989 de 28 de febrero sobre Ingreso Mínimo Familiar del Gobierno vasco ${ }^{33}$. A este le siguieron otros que, como en el caso vasco, siguieron el modelo de la Revenue Minime d'Insertion francesa. Esta primera fase concluye en 1995 con la aprobación de una renta mínima en las Islas Baleares.

La función de estos programas tendría que haber sido cubrir los huecos dejados por el conjunto de prestaciones de mínimos, sobre todo a aquellos colectivos pobres o excluidos pero que en principio son aptos para el trabajo remunerado y que, además, no tienen acceso a prestaciones asistenciales como los subsidios de desempleo. Sin embargo, durante todo el periodo de

32 J. Elster: «Comentario sobre Van der Veen y Van Parijs», trad. de Fernando Aguiar, Zona Abierta, núm. 46-47, 1988, pp. 113-114.

${ }^{33}$ Aquí también son visibles las consecuencias derivadas de que, como dijo Joseph Fontana, el franquismo retrasara «el reloj de la historia». El inicio de la aplicación de las rentas mínimas en Europa se lleva a cabo en tres olas: 1) una primera se situaría entre 1930 y 1970, coincidiendo con la era fordista de bonanza económica y social que dio lugar a la expansión del Estado del bienestar. En esta época se aprueba el primer programa de rentas mínimas en Dinamarca en 1933, seguido por Gran Bretaña, Alemania, Holanda, Austria, Suecia y Finlandia; 2) una segunda ola, entre 1970 y 1985, en que se crea el Minimex belga en 1974 y el sistema irlandés en 1977; 3) por último, la tercera etapa se sitúa entre 1985 y 1995, con la adopción de los programas de Luxemburgo, Francia, España, Italia y Portugal. 
crecimiento económico continuado en España, el gasto público involucrado en el mantenimiento de estos programas ha sido pequeño (apenas un $0,3 \%$ en promedio de los presupuestos autonómicos en 2000) $)^{34}$. Un estudio realizado en 1998 planteaba la necesidad de unos 160.000 millones para completar realmente el sistema de garantía de ingresos mínimos ${ }^{35}$. Pero por estas mismas fechas se abre una segunda etapa en el proceso de implantación de rentas mínimas, también por el Gobierno vasco, con la Ley 12/1998 contra la exclusión social; a partir de entonces, los mecanismos de inserción no se van a limitar ya a la prestación económica, sino que van a tratar de ofrecer una solución integral al proceso de exclusión, previendo el desarrollo de un conjunto de actuaciones orientadas a la inserción.

Esta nueva forma en que se concibe la inserción y su relación con la prestación económica se conoce como principio del doble derecho. En la reciente Ley 18/2008, de 23 de diciembre, de Garantía de Ingresos y para la Inclusión Social del Gobierno vasco, se mantiene este principio, por el que los colectivos desprotegidos tendrían tanto derecho a los ingresos mínimos que no consiguen alcanzar por carecer de trabajo, o de una prestación alternativa de cuantía suficiente, como a participar en las acciones de inserción que le permitan solucionar sus problemas por las vías que se entienden como normalizadas. El instrumento operativo en el ámbito de la inserción es el convenio de inserción, y aunque no desaparece del todo, el principio de negociación que regía las relaciones entre las partes queda sustancialmente diluido en la nueva Ley para la Garantía de Ingresos vasca (art. 88f).

El modo más simple de describir la Renta Básica para la Inclusión y Protección Social ${ }^{36}$ vasca es que se trata de un contrato; así, facilita una ayuda económica como prestación no contributiva a cambio de participar en un programa de inclusión social. Un contrato cuyos efectos dependen además

\footnotetext{
${ }^{34}$ L. Moreno y otros: «¿Existe una «malla de seguridad» en la Europa del sur?», op. cit., p. 6.

${ }^{35}$ A. Serrano y A. Arriba: ¿Pobres o excluidos? El Ingreso Madrileño de Integración en perspectiva comparada, Fundación Argentaria-Visor, Madrid.

${ }^{36}$ Una de las principales novedades de la ley es que la prestación denominada Renta de Garantía de Ingresos, que ya está considerada como derecho subjetivo, se articula en tres modalidades diferenciadas en función de dos criterios básicos: por un lado, la existencia o no de ingresos en la unidad de convivencia y, en su caso, la procedencia de dichos ingresos -bien rentas de pensiones (100\% del SMI), bien rentas de trabajo (88\% SMI), más incentivos al empleo-; y, por otro, el tipo de vinculación de cada una de estas modalidades a un convenio de inclusión laboral. De modo que existirán tres modalidades: 1) la Renta Básica para la Inclusión y Protección Social, dirigida a las personas y unidades convivenciales que carecen de recursos económicos propios y que irá siempre acompañada de la firma de un convenio de inclusión; 2) la Renta Complementaria de Pensiones, destinada a personas perceptoras de pensiones tanto contributivas como no contributivas; 3 ) la Renta Complementaria de Ingresos de Trabajo, dirigida a personas que disponen de rentas de trabajo, pero cuyo nivel mensual de ingresos no alcanza el importe de la Renta Básica para la Inclusión y Protección Social.
} 
de que el beneficiario realice determinados trabajos, actividades formativas o no practique la mendicidad ni permita su práctica a otros miembros de la unidad de convivencia. Esto es, un contrato sujeto a la condición potestativa que regula el art. 1.115 del Código Civil y que este permite, pues al establecer que la condición cuyo cumplimiento dependa de la exclusiva voluntad del obligado anula la obligación de que dependa, es admisible que no se dé este efecto cuando no haya esa dependencia exclusiva ${ }^{37}$. Pero al margen de esta cuestión, el mayor inconveniente que en la práctica presenta el modelo de inclusión social en Euskadi es que descansa en la «centralidad del empleo como herramienta de inclusión social» ${ }^{38}$.

Siguiendo con lo apuntado más arriba (2.1), la legislación sobre exclusión social tiene que comprehender que, a diferencia de lo que ocurría en la «época dorada del capitalismo de bienestar» o fordista, hoy el paro ha dejado de ser un fenómeno aislado, coyuntural, para convertirse en un elemento estructural en nuestras sociedades. Cuando lo que está en cuestión es precisamente si los mercados de trabajo actuales tienen la suficiente capacidad o no de dar trabajo a todos ${ }^{39}$, la solución no puede pasar por un modelo de

${ }^{37}$ Luis Díez Picazo y Antonio Gullón consideran «acertada la doctrina que ve en la primera [condición puramente potestativa] una voluntad de la que nace un acto que es indiferente realizar (si te saludo, si quiero, etc.), mientras que en la segunda [condición simplemente potestativa] operan sobre la voluntad una serie de motivos que son de libre estimación, pero que representan intereses, dificultades o apetencias a tener en cuenta para mover aquella en un sentido o en otro»; Sistema de derecho civil, vol. II, p. 96. No parece muy disparatado pensar que sobre la voluntad de una persona que se encuentra de hecho en una situación de exclusión operan una serie de dificultades (ausencia de redes sociales, de vivienda, toxicomanías, etc.) a tener en cuenta.

${ }^{38}$ Departamento de Justicia, Empleo y Seguridad Social, «La Ley para la Garantía de Ingresos y para la Inclusión Social, en Euskadi», ponencia presentada en la Jornada de Presentació de L'Observatori Social de les Illes Balears. La Inclusió Social a les Illes Balears, Palma de Mallorca, 25 de febrero de 2009. Un resumen de la presentación en Microsoft PowerPoint puede consultarse en <www.uib.es/gi/osib/docs/feb09/llei_euskadi.pdf>.

${ }^{39}$ Han sido muchos los autores que, en el ámbito de las ciencias sociales, han presentado trabajos en que tratan la crisis del trabajo. Así, por ejemplo, en El fin del trabajo, Jeremy Rifkin sostiene la tesis de que los cambios tecnológicos de la era postfordista tienen como consecuencia la eliminación de una gran cantidad de empleos. Como solución a esta progresiva tendencia hacia la disolución de la centralidad del empleo en las biografías de las personas, Rifkin propone que aquellos que no puedan acceder al mercado laboral se incorporen a un tercer sector, «el de la economía social, el que se supone que en el siglo [XXI] ayudará a dirigir las necesidades personales y sociales que no pueden ser conformadas a través de las leyes del mercado». Una propuesta similar es la que plantea Ulrich Beck en Un nuevo mundo feliz; su tesis principal es que la sociedad del pleno empleo y, por consiguiente, el trabajo como mecanismo de integración social, es un modelo que ha entrado en crisis como resultado de los aumentos en la productividad, los procesos de globalización y el crecimiento de las formas de empleo precario. Ante este panorama, el remedio que propone consiste en el diseño de nuevas formas de trabajo, o «trabajo de compromiso civil retribuido», configurado como un trabajo voluntario y retribuido por medio de derechos de pensión, créditos y dinero cívico. 
inserción fundamentado en la centralidad del empleo como herramienta de inclusión social, «porque lo laboral es precisamente lo que ya no funciona como mecanismo de integración ${ }^{40}$. Hasta el momento, las rentas mínimas en España responden a una lógica asistencial y no pretenden sino ejercer un control más directo sobre los beneficiarios, de ahí que estén sujetas tanto a prueba de necesidad como a la obligación de contribuir con la sociedad de la única forma que contemplan los programas de workfare: integrándose en el mercado laboral. El resultado es que las rentas mínimas llegan en España a 7 de cada 1.000 hogares (unos 115.000), una cantidad sin duda muy reducida si, concebidos como última red de seguridad destinada a garantizar unos ingresos mínimos a aquellos sectores más desfavorecidos, tenemos en cuenta que, de acuerdo con la encuesta FOESSA 2007, el porcentaje de hogares que se encontraban en España en situación de pobreza severa oscilaría entre el $4,1 \%$ y el 3,4\%, lo que supondría entre 675.000 y 560.000 hogares $^{41}$.

Por otro lado, el sistema de garantía de ingresos español aún sigue tomando como punto de partida de partida a la familia, no al individuo. A pesar de los avances observables en algunas legislaciones sobre rentas mínimas (así, la Ley Contra la Exclusión vasca habla de «unidad de económica de convivencia»), lo que se tiene en cuenta a la hora de calcular la cuantía de las prestaciones económicas son los ingresos de todas las personas del hogar. Ocurre además que la forma de calcular la prestación penaliza en casi todos los casos a las familias más numerosas, pues opera mediante economías de escala $^{42}$. La combinación de un concepto amplio de familia con las referidas economías para el cómputo de la prestación tiene una gran trascendencia en el análisis de la incidencia de las rentas mínimas, pues reduce de forma muy notable tanto su cuantía como la extensión de su cobertura.

\footnotetext{
${ }^{40}$ José Luis Rey Pérez: «El Derecho al Trabajo, ¿forma de exclusión social? Las Rentas Mínimas de Integración y las propuestas del Ingreso Básico», ICADE, Revista de las Facultades de Derecho y de Empresariales, núm. 62, abril-mayo, p. 23.

${ }^{41}$ Se define la pobreza severa como la situada bajo el umbral del $30 \%$ de la renta mediana por unidad de consumo.

${ }^{42}$ Esta forma de cómputo ha recibido críticas porque «la cuantía asignada por cada miembro adicional es relativamente plana, es decir, que no crece lo que parece necesitar cada miembro adicional, donde no podemos dejar de leer un cierto intento de penalizar a minorías étnicas que tradicionalmente constituyen familias numerosas. Por otro lado, este tratamiento perjudicial hacia las unidades más numerosas resulta agravado por el hecho de que algunas comunidades establecen unos máximos en las cantidades finales a recibir, con lo que llega un momento en que el aumento de componentes en la unidad familiar no se traduce en un aumento de la prestación económica»; R. Susín: La regulación de la pobreza, Universidad de La Rioja, Logroño, 2000, p. 326. Citado por J. L. Rey Pérez: «El derecho al trabajo, ¿forma de exclusión social?», op. cit., p. 21.
} 


\subsubsection{CAUSAS DE CARÁCTER IDEOLÓGICO}

Desde una perspectiva filosófica, la circunstancia de que las prestaciones de asistencia social en España respondan más a una «función latente de control-censura social llevada a cabo a través de los ingresos mínimos $\gg^{43}$ que a la de cubrir los agujeros dejados por el conjunto del sistema de mantenimiento de ingresos mínimos se explica en atención a la concepción de la igualdad a la que históricamente dieron respuesta estas instituciones. Es más, de acuerdo con esta tesis, la escasa protección que ofrecen las mallas de seguridad de los países del Sur de Europa se relacionaría causalmente no solo con unas «pautas socioeconómicas complejas, una limitada capacidad administrativa y un persistente fraude fiscal» específicamente meridionales ${ }^{44}$, sino también con un enfoque de la igualdad característica de los Gobiernos conservadores y presente en los regímenes dictatoriales meridionales.

En lo tocante a España, durante la dictadura del general Franco los programas de asistencia social eran prácticamente inexistentes. La justicia social no era un tema dentro de la agenda política del régimen, que delegaba la provisión del bienestar en la estructura tradicional familiar y las instituciones caritativas gestionadas de modo más o menos directo por la Iglesia católica. Lo mismo cabe decir respecto de los casos de Grecia y Portugal. En cuanto al primero, la restauración de la democracia en 1974 produjo un incremento sin precedentes del gasto social, en parte como respuesta a las expectativas de una parte importante de la población discriminada durante décadas ${ }^{45}$. Por el otro lado, en los años que siguieron a la Revolución de los Claveles en 1974, Portugal fue implantando un conjunto de derechos e instituciones sociales que dan forma a su actual Estado de bienestar. Sin embargo, y como consecuencia de las tensiones golpistas que, como en los casos de Grecia y España, siguieron a la aprobación de la Constitución de 1976, los recursos financieros necesarios para reorganizar un servicio de protección social raquítico durante todo el período del Estado Novo no llegarían hasta 1986, con su integración en la Comunidad Económica Europea.

Tras 30 años de Gobiernos democráticos de diverso color político, se constata aún hoy un significativo subdesarrollo social en el contexto de los países europeos meridionales. El hecho de haber permanecido al margen de las políticas fiscales keynesianas que posibilitaron la construcción de los Estados de bienestar en la Europa democrática lleva aparejada una cierta des-

\footnotetext{
${ }^{43}$ R. Susín: La regulación de la pobreza, op. cit., p. 347.

${ }^{44}$ M. Aguilar, M. Laparra y M. Gaviria: La caña y el pez: el salario social en las comunidades autónomas 1989-1994, FOESSA, Madrid.

${ }^{45}$ L. Moreno y otros: «¿Existe una "malla de seguridad” en la Europa del sur?», op. cit., pp. 8 a 11. Una recomendación para aquellos que estén interesados en el caso griego y disfruten con el cine de corte político: Z., película dirigida en 1969 por Constantin CostaGavras.
} 
convergencia social de la que la historiografía da cuenta solo en parte. La otra circunstancia a tomar en consideración es que la corriente de pensamiento neoliberal en que hallan su fundamento ideológico las Reaganomics irrumpe en el mundo occidental a comienzos de los ochenta; es decir, al mismo tiempo que los referidos países del Sur de Europa comenzaban a configurar sus Estados del bienestar.

No es este el lugar para analizar la importancia del liberalismo como doctrina que, al igual que, por ejemplo, el marxismo, hizo de la libertad de las personas su causa. Tampoco para verificar si el neoliberalismo pertenece a la misma familia de ideas que el liberalismo clásico. Aquí tan solo importa observar que tanto la tradición cristiana como la escuela neoliberal invocan una concepción de la igualdad coincidente en un punto: el principio de que quien no trabaja no debe comer. De acuerdo con esta visión de la justicia social, los derechos sociales pasan a ser confundidos con la caridad privada de instituciones más o menos relacionadas con la Iglesia o con la beneficencia pública, que ofrecen la asistencia como acto de buena voluntad del Estado, con la condición, eso sí, de que se merezca; esto es, siempre que se trabaje, pues en estos esquemas asistenciales no existen instituciones que den cobertura con un alcance universal.

El convencimiento de que mecanismos como los de las rentas mínimas no sirven para erradicar las situaciones de pobreza más severa ni han demostrado hasta el momento una capacidad mínima de respuesta ante la actual crisis económica hace que parezca pertinente la presentación de propuestas alternativas.

\section{La propuesta de la Renta Básica}

La Renta Básica (RB) es un ingreso pagado por el Estado a cada miembro de la sociedad, incluso si no quiere trabajar de forma remunerada, sin tomar en consideración si es rico o pobre o, dicho de otra forma, independientemente de cuáles puedan ser las otras posibles fuentes de renta, y sin importar con quién conviva ${ }^{46}$. Pero antes de nada, aplicaremos la teoría general de las condiciones que se necesitan para realizar reformas sociales a gran escala sugerida por Elster y a la que hacíamos mención más arriba.

Ahora solo recordaré que, según la teoría, hay básicamente dos tipos de argumentos a favor de la reforma: por un lado, los de tipo consecuencialista,

${ }^{46}$ Esta es la definición más extendida de la Renta Básica y sobre la que existe un cierto consenso en la doctrina. Así, y sin afán exhaustivo, se puede encontrar en D. Raventós (coord.): La Renta Básica. Por una ciudadanía más libre, más igualitaria y más fraterna, Ariel, 2001, p. 22; o P. Van Parijs: Libertad real para todos. Qué puede justificar el capitalismo (si hay algo que pueda hacerlo), Barcelona, Paidós, 1996. 
de acuerdo con que la reforma se desea porque se cree que tendrá consecuencias deseables; por otro lado, los deontológicos o principle-based arguments, a cuya luz se considera que la reforma es intrínsecamente valiosa. Comenzaré con una breve exposición de estos últimos, en la convicción, compartida con Daniel Raventós, de que «de poco serviría una medida social que fuera política o económicamente viable si no fuera éticamente deseable [...] Con su aceptación social no está garantizado el éxito, pero sin esta aceptación está asegurado su fracaso» ${ }^{47}$.

Las teorías actuales de la justicia, según Dworkin, comparten todas ellas el mismo valor último, que es la igualdad. En lo que divergen, pues, es en la elección del criterio en que sea deseable una cierta igualdad. La cuestión que permanece abierta en la filosofía política contemporánea es, por decirlo con Amartya Sen, «igualdad de qué? ${ }^{48}$. Pues bien, hasta ahora la RB se ha tratado de justificar normativamente sobre la base de las siguientes dos principales concepciones de la justicia distributiva: la igualdad de bienestar marxiana y la igualdad de acceso a la herencia común del republicanismo propietarista.

Comenzando por la primera, en 1986 Philippe Van Parijs y Robert J. van der Veen publicaron un artículo titulado «Una vía capitalista al comunismo» en la prestigiosa revista Theory and Society ${ }^{49}$. El argumento de estos autores se puede resumir de la siguiente forma: mientras el comunismo tiene como fin la supresión de la alienación, el socialismo, al promover la propiedad colectiva de los medios de producción, implica la abolición de la explotación, ya que los trabajadores se apropian del producto social en su totalidad. El socialismo no es la única vía para llegar al comunismo, ni siquiera es una vía necesaria, pues no parece que la colectivización de los medios de producción sea un requisito imprescindible para acabar con la alienación. Pero aun si el socialismo ya no resulta instrumentalmente necesario para alcanzar la fase superior del comunismo - pues el capitalismo puede ser tanto o más eficaz que el socialismo en lo atinente al crecimiento de la productividad del trabajo-, todavía hay otra manera directamente ética de justificar el socialismo frente al capitalismo: no como un instrumento más eficaz para operar la transición, sino como intrínsecamente más justo y, por tanto, normativamente superior.

En este punto surge, sin embargo, un problema. Es dudoso que Marx defendiera algún modelo de justicia distributiva. Así, mientras que para autores como R. C. Tucker o A. Wood no es solo que Marx entendiera la justicia como un valor superfluo en la sociedad de la abundancia del comunismo,

${ }^{47}$ D. Raventós: El derecho a la existencia, op. cit., p. 23.

${ }^{48}$ Amartya Sen: Nuevo examen de la desigualdad, Alianza, Madrid, 1995.

${ }^{49}$ Theory and Society, n. ${ }^{\circ} 15,1986$. Citaré por la atenta traducción de Natalia G. Pardo publicada por la revista Zona Abierta, n. ${ }^{\circ}$ 46-47, enero-junio, 1988. 
sino que objetaba incluso el principio de igualdad moral subyacente a esta, en opinión de Van Parijs y Van der Veen, Marx adopta una postura mucho más comprometida con el valor de la justicia, que se resumen en el enunciado «de cada uno según sus capacidades y cada cual según sus necesidades», tal como se describe en la Crítica del programa de Gotha. Este es, en efecto, el criterio de distribución de la igualdad de bienestar, procedente de la tradición socialista utópica, y en concreto de Louis Blanc. Para Marx, y frente al sistema de retribución conforme a las capacidades, el único criterio de distribución que igualaría con justicia a individuos desigualmente dotados sería el que considera las necesidades de las personas, entendidas no como necesidades básicas, sino en atención a la diferencia y la mayor variedad y riqueza de necesidades según distintos sujetos. La cuestión radica entonces, para P. V. P. y R. van der Veen, en si es posible introducir alguna medida de reforma dentro del capitalismo que permita la satisfacción de este criterio de justicia en las distribuciones operadas en las sociedades contemporáneas. Esta institución es la RB. Y es que con su implantación se lograría abolir la alienación, principal objetivo del comunismo, pues una vez cubiertas las necesidades fundamentales de todos los individuos, nadie se vería obligado a trabajar para poder existir.

Dada su intención explicitada de «mantenerse dentro de un marco teórico marxiano razonablemente ortodoxo» en el que la cuestión de la justicia y otras consideraciones éticas son secundarias, parece poco pertinente elaborar una crítica sobre aspectos normativos que los propios autores rechazan ${ }^{50}$. Según el marxismo clásico, llegamos a la igualdad a través y como resultado de la historia. Por ello, solo apuntaré tres críticas que, en la medida en que se me antojan difícilmente salvables, hacen de la igualdad de bienestar un criterio distributivo inoperante:

1..$\left.^{\circ}\right)$ No salva la objeción del esclavo satisfecho, pues las personas con mayores capacidades adaptativas recibirán menos medios.

2. $\left.{ }^{\circ}\right)$ Puede favorecer la irresponsabilidad individual y el desarrollo de gustos caros en algunas personas, y que ello contribuya a disminuir el bienestar de otras, que acabarían pagando por caprichos extravagantes y ajenos.

\footnotetext{
${ }^{50}$ En este sentido, para P. V. P. y R. van der Veen «lo que importa realmente cuando se valora un modo de producción no es hasta qué punto el producto social se reparte equitativamente, sino hasta qué punto estimula efectivamente el desarrollo productivo en dirección al comunismo pleno» (Van der Veen y Van Parijs, 1988, p. 29). Antes de la caída del comunismo europeo, los marxistas -o al menos algunos de ellos- vivían en la fe de que la consumación de siglos de explotación y lucha de clases sería una condición de la abundancia material que permitiría la autorrealización de todas las personas, en una sociedad en la que «el libre desarrollo de cada uno será la condición del libre desarrollo de todos» (Marx, 1848). Hoy, los marxistas analíticos han comprendido que, pese a la relativa abundancia de las sociedades occidentales modernas, la escasez se ha convertido en un problema crónico, y entienden «la cuestión de la justicia» como una cuestión primordial, y el criterio de las necesidades como un principio de justicia distributiva.
} 
3..$^{\circ}$ El bienestar no parece ser ni lo único ni lo más valioso, y además en las sociedades modernas y diversas las personas razonablemente divergirán sobre los elementos constitutivos de la vida buena.

Debido a los problemas que suscita el enfoque de la igualdad de bienestar, interesa señalar que el propio Van Parijs abandonó su inicial defensa marxista de la institución en el que seguramente constituya el mayor esfuerzo realizado hasta ahora por justificar normativamente la RB: Real Freedom For All. What (if anything) can justify capitalism. En este libro, y como es de esperar a tenor de su provocativo título, la conclusión que finalmente se alcanza es la de que el capitalismo es un sistema productivo superior al socialismo que, no obstante, solo resulta normativamente justificable en tanto incluya la institución de la RB.

Pero además de Van Parijs, otros muchos filósofos políticos han hecho intentos por justificar la RB desde enfoques muy distintos al de la igualdad de bienestar. Por su seriedad y rigor, así como por estar concebidos para el caso particular de España, merecen destacarse aquí los trabajos de José Luis Rey Pérez, Daniel Raventós, David Casassas o Antoni Doménech. Con la posible excepción del primero, es significativo el hecho de que el resto hayan optado por una defensa declaradamente republicana de la institución, en la que se pueden presentar conjuntamente las dos vías de argumentar-consecuencialistas y deontológicos- a favor de la RB. Unos argumentos que siquiera toman singular fuerza en un tiempo de crisis económica como el actual, fueron elaborados con una contundencia aún mayor hace ya más de dos siglos.

Thomas Paine comienza su «Argumento para mejorar la condición de los pobres» con la observación de que «preservar los beneficios de lo que se considera vida civilizada, y remediar, al mismo tiempo, los males que ella ha originado, debería ser considerado uno de los principales objetivos de una legislación moderna». Esta reflexión se encuentra recogida en El sentido común y otros ensayos y data de 1797. Su discurso suena, empero, contemporáneo. Y no solo porque continúa siendo urgente alumbrar soluciones que mejoren la situación de los pobres, sino también porque el argumento que inspira su Fondo Nacional es esencialmente el que aconseja hoy la adopción de una RB. Desde un punto de vista republicano, los derechos sociales no pueden ser confundidos con la beneficencia. La caridad pública (y privada), aunque loable, es incompatible con una concepción republicana de la ciudadanía, pues ofende la dignidad de quien la recibe. Si necesito ayuda porque soy pobre, o porque estoy enfermo, prefiero que dicha ayuda proceda del reconocimiento de mi derecho como ciudadano, antes que de la acción de un individuo en nombre del amor a Jesucristo. Estar enfermo o ser anciano no es una culpa, y un Estado republicano, a pesar de que muchos lo ignoren, no es una sociedad anónima, sino una forma de vida en común cuyo objetivo es garantizar la dignidad de las personas. Un Estado republicano debe asumir por consiguiente la responsabilidad de asistir a su ciudadanía sin encomen- 
dar esa tarea a individuos particulares. Se mire por donde se mire, es preferible recibir ayuda en nombre de los derechos sociales que como resultado del ejercicio de la caridad cristiana. En una época, muy alejada del modelo socio-productivo fordista, que se caracteriza por elevadas tasas de paro y la extensión de la flexibilidad y la precarización de las condiciones del trabajo, los más recientes desarrollos legislativos sobre rentas mínimas como la Ley de Garantía de Ingresos vasca insiste en la centralidad del empleo como herramienta de inclusión social. Pero esta decisión no es tan incomprensible como a primera vista parece. Y es que mientras desde una perspectiva republicana la ayuda a quienes la necesitan se da y justifica por el principio de la igual dignidad de todas las personas y se recibe en nombre de los derechos, desde una óptica neoconservadora aquella se da (o no) por caridad y se recibe (o no) en nombre de Pablo.

\section{Bibliografía}

Aguilar, M., LAPARRA, M. y GAVIRIA, M. (1995): La caña y el pez: el salario social en las comunidades autónomas 1989-1994, FOESSA, Madrid.

ARISTÓTELES (1989a): Ética a Nicómaco, edición de M. Araujo y J. Marías, Centro de Estudios Constitucionales, Madrid.

(1989b): Política, edición de M. Araujo y J. Marías, Centro de Estudios Constitucionales, Madrid.

Alperovitz, G. (2005): «Time to Get Serious about Inequality and Sustainability», Synthesis/Regeneration 38.

BARRY, B. (1997): Justicia como imparcialidad, Paidós, Barcelona.

BECK, U. (2000): Un nuevo mundo feliz. La precariedad del trabajo en la era de la globalización, Paidós, Barcelona.

CASTEL, R. (1999): Les metamorphoses de la question sociale. Une chronique de salariat, Gallimard, París.

Comín, F. (2003): «La Hacienda pública en el franquismo autárquico, 19401959», en Autarquía y mercado negro: el fracaso económico del primer franquismo, 1939-1959, Carlos F. Barciela, ed., Ed. Crítica, Barcelona.

Comisión Mundial sobre las Dimensiones Sociales de la Globalización (2004): Por una globalización justa: crear oportunidades para todos, Organización Internacional del Trabajo.

Departamento de Justicia, Empleo y Seguridad Social del Gobierno VASCO (2009): «La Ley para la Garantía de Ingresos y para la Inclusión Social, en Euskadi», ponencia presentada en la Jornada de Presentació de L'Observatori Social de les Illes Balears. La Inclusió Social a les Illes Balears, Palma de Mallorca.

DíEz Picazo, L. y Gullón, A. (1999): Sistema de derecho civil, vol. II, Tecnos, octava Edición, Madrid. 
ElsteR, J. (1988): «Comentario sobre Van der Veen y Van Parijs», trad. de Fernando Aguiar, Zona Abierta, núm. 46-47.

EsPing-ANDERSEN, G. (1993): Los tres mundos del Estado del Bienestar, trad. B. Arregui Luco, Edicions Alfons el Magnànim-IVEI, Valencia.

Fondo Monetario InTERnacional (2004): Informe anual del Directorio Ejecutivo correspondiente al ejercicio cerrado el 30 de abril de 2004, Washington, D. C.

Laparra, M. y Ayala, L. (2007): «El Sistema de Garantía de Ingresos Mínimos en España y la respuesta urgente que requiere la crisis social», Colecciones FOESSA.

Marlier, E. y COHEN-Solal, M. (2000): «Social benefits and their redistributive effect in the EU», Statistics in Focus (Theme 3 9/2000), Eurostat, Luxemburgo.

Miguélez, F. (2002): «¿Por qué empeora el empleo?», Sistema, núm. 168169, pp. 37-53.

Moreno, L., Matsaganis, M., Ferrera M. y Capucha, L. (2003): «iExiste una "malla de seguridad" en la Europa del Sur? La lucha contra la pobreza y la exclusión social en España, Grecia, Italia y Portugal», en Digital.CSIC, Unidad de Políticas Comparadas (CSIC), Documento de Trabajo 03-17.

Navarro, V. (2006): El subdesarrollo social de España. Causas y consecuencias, Ed. Anagrama, Barcelona.

Navarro, V., Schmitt, J. y Astudillo, J. (2002): «La importancia de la política en la supuesta globalización económica. La evolución de los Estados del Bienestar en el capitalismo desarrollado durante la década de los años noventa», Sistema, núm. 171, pp. 3-46.

Nozick, R. (1974): Anarchy, State, and Utopia, Basic Books, inc., Nueva York.

Programa de las Naciones Unidas Para el Desarrollo (2009): Informe sobre Desarrollo Humano 2009.

RAVENTós, D. (1999): El derecho a la existencia. La propuesta del subsidio universal garantizado, Ariel, Barcelona.

RAwLS, J. (1985): «Justice as Fairness: Political not Metaphysical», Philosophy and Public Affairs, vol. 14, n. ${ }^{\circ}$ 3, pp. 223-251.

Rey PÉREZ, J. L. (2004): «El Derecho al Trabajo, ¿forma de exclusión social? Las Rentas Mínimas de Integración y las propuestas del Ingreso Básico», ICADE, Revista de las Facultades de Derecho y de Empresariales, núm. 62, abril-mayo.

RIFKIN, J. (1972): El fin del trabajo. Nuevas tecnologías contra puestos de trabajo; el nacimiento de una nueva era, Paidós, Barcelona.

Russell, B. (1969): Ensayos Filosóficos, Alianza Editorial, Madrid.

SERrano, A. y Arriba, A. (1998): ¿Pobres o excluidos? El Ingreso Madrileño de Integración en perspectiva comparada, Fundación ArgentariaVisor, Madrid. 
Susín, R. (2000): La regulación de la pobreza, Universidad de La Rioja, Logroño.

VALDÉS DAL-RÉ, F. (2002): «Descentralización productiva y desorganización del Derecho del Trabajo», Revista de Ciencias Sociales, núm. 168-169, pp. 71-88.

VAN DER VEen, R. J. y VAN PARIJS, P. (1988): «Una vía capitalista al comunismo», trad. N. G. Pardo, Zona Abierta, n. ${ }^{\circ}$ 46-47, enero-junio, pp. 1946.

VAN PARIJS, P. (1996): Libertad real para todos. Qué puede justificar al capitalismo (si hay algo que pueda hacerlo), trad. J. Francisco Álvarez, Paidós, Barcelona.

VERGARA, F. (1999): Introducción a los fundamentos filosóficos del liberalismo, Alianza, Madrid. 